\title{
Controle de fungos presentes no ar e em sementes de feijão durante armazenamento
}

\author{
Flávio M. Borém ${ }^{1}$, Osvaldo Resende ${ }^{2}$, José da C. Machado ${ }^{3}$, Isa M. R. Fontenelle ${ }^{4}$ Frederico F. de Sousa ${ }^{1}$
}

\begin{abstract}
RESUMO
Objetivou-se, no presente trabalho, avaliar a eficácia de um equipamento redutor de inóculo (ERI) na preservação da qualidade sanitária de sementes de feijão (Phaseolus vulgaris L.) durante o armazenamento em estruturas herméticas com circulação de ar forçado. A presença de inóculo no ar foi monitorada a partir da exposição de placas de Petri com meio de cultura BDA salino, contando-se o número de unidades formadoras de colônias (UFC) dos fungos Aspergillus spp. e Penicillium spp. As análises sanitárias das sementes foram realizada pelo método do papel de filtro (Blotter test), calculando-se o índice de ocorrência de Aspergillus spp. e Penicillium spp. Durante o período de armazenamento, houve um aumento na incidência de fungos nas sementes, independente da presença dos ERI. Nas amostragens realizadas na entrada da caixa com a presença dos ERI, não foram encontradas unidades formadoras de colônias. Com o aumento do fluxo de ar utilizado no sistema, notou-se que este efeito foi transferido para a saída da caixa. Nas condições especificadas, os ERI foram incapazes de controlar os fungos de armazenamento, Aspergillus spp e Penicillium spp, nas sementes de feijão, porém foram eficazes no controle dos seus esporos presentes no ar.
\end{abstract}

Palavras-chave: equipamento redutor de inóculo, sanidade de sementes, Aspergillus

\section{Control of fungi present in the air and bean seeds during storage}

\begin{abstract}
The objective of the present work was to evaluate the efficiency of inoculum reducing equipment (IRE) in the maintenance of quality of bean seeds during storage in hermetic structures with circulation of forced air. The inoculum's presence in the air was monitored by the exposition of Petri dishes with culture medium (saline BDA) by counting the number of colonies units of Aspergillus and Penicillium. The quality analysis of seeds were performed by the blotter test. The occurrence index was calculated for Aspergillus spp and Penicillium spp. The fungal occurrence increased during the storage period, in spite of the IRE presence. Fungal colonies were not found in the air samples collected at the box entrance, holding IRE. As the airflow used in the system was increased, the effect of the equipment has been moved to the box exit. For the conditions of this work, the IRE were not capable to control the storage fungi in the seeds, however were efficient to control the spores in the air.
\end{abstract}

Key words: reducing inoculum deveice, seeds health, Aspergillus.

${ }^{1}$ Departamento de Engenharia, UFLA, CP 37, CEP 37 200.000, Lavras, MG. Fone: (35) 3829 1488. E-mail: flavioborem@ufla.br

2 Departamento de Ciência dos Alimentos/UFLA. E-mail: osvresende@yahoo.com.br

${ }^{3}$ Departamento de Fitopatologia/UFLA. Fone: (35) 3829 1427, E-mail: machado@ufla.br

${ }^{4}$ Bolsista de Iniciação Científica da FAPEMIG. Departamento de Engenharia/UFLA. Fone: (35) 3829-1220. E-mail: isarezende@hotmail.com; faula@ufla.br 


\section{INTRODUÇÃO}

Os fungos que ocorrem nas sementes podem ser divididos em dois grupos: de campo e de armazenamento. Os primeiros causam doenças nas plantas em desenvolvimento e, transmitidos por sementes, podem danificá-las, desde que estas estejam mantidas sob condições inadequadas de armazenamento. O segundo grupo de fungos compreende principalmente espécies de Aspergillus e Penicillium, podendo estar presentes como contaminantes, ou na forma de micélios dormentes entre os tecidos do pericarpo ou do tegumento das sementes. Podem desenvolver e provocar danos às sementes durante o armazenamento. A temperatura e umidade relativa do ar são os principais fatores do ambiente que influenciam o desenvolvimento de fungos, verificando-se em decorrência, apodrecimentos, redução da germinação, desenvolvimento de plântular anormais e outros (Machado 2000; Neergaard, 1979; Christensen, 1974; Novembre, 1987).

A temperatura ótima para o crescimento e desenvolvimento da maioria dos fungos de armazenamento encontrase entre 28 e $35^{\circ} \mathrm{C}$, estando a máxima e a mínima, respectivamente, entre 50 e $55^{\circ} \mathrm{C}$ e 0 e $5^{\circ} \mathrm{C}$ (Dhingra, 1985). A atividade de fungos decai prontamente com a redução da temperatura e algumas espécies de Aspergillus spp. podem chegar a ampliar sua população 10 a 20 vezes mais rápido quando a temperatura for de $15{ }^{\circ} \mathrm{C}$ para $32{ }^{\circ} \mathrm{C}$ (Carvalho \& von Pinho, 1997).

Atualmente, tem-se procurado métodos alternativos para armazenar grãos com controle eficiente de pragas garantindo-se a oferta de produtos agrícolas com elevado padrão de qualidade sensorial e higiênico sanitário.

Um sistema de armazenamento que utiliza um equipamento modificador da atmosfera, foi capaz de conservar amêndoas de cacau por períodos de até 10 meses, mantendo todas as suas características desejáveis, além de drástica redução da população de fungos, dispensando a utilização de substâncias químicas (Hara et al., 1990, citado por Borém et al., 2001a). O princípio de funcionamento desse equipamento ocorre por meio de convecção natural; desta forma, o ar é levado ao interior do equipamento atravessando os filamentos da resistência elétrica, atingindo uma temperatura de aproximadamente $325^{\circ} \mathrm{C}$ (Borém et al.,1998) responsável pela esterilização dessa camada de ar.

Baez (1993) verificou que a utilização do equipamento modificador de atmosfera em condições de elevadas temperatura e umidade relativa, $30^{\circ} \mathrm{C}$ e $93 \%$, respectivamente, inibiu, durante 10 dias de armazenamento, o crescimento de fungos em grãos de milho sem a secagem e a adição de produtos químicos.

As alterações químicas e físicas que este equipamento provoca no ar, foram avaliadas por Borém et al. (1998) que constataram que o mesmo foi capaz de ionizar o ar, porém numa escala bastante reduzida; além disso, concluíram que o equipamento não liberou substâncias como enxofre, nem compostos orgânicos, especialmente fenóis; entretanto, constataram a produção de $\mathrm{CO}_{2}$ proveniente tanto da oxidação de matéria orgânica como de outras reações químicas ocor- ridas no bloco cerâmico. A oxidação de inóculos seria, até o momento, a hipótese mais provável para explicar o efeito do equipamento relatado anteriormente, sendo notável a necessidade de novas pesquisas para maiores esclarecimentos.

Borém et al. (2001b) estudaram o efeito do equipamento modificador de atmosfera no desenvolvimento de fungos em sementes de feijão, em ambientes com $30{ }^{\circ} \mathrm{C}$ de temperatura e 95\% de umidade relativa. A partir dos resultados obtidos, concluíram que o equipamento apresentou efeito restrito às suas proximidades, sendo capaz de impedir o desenvolvimento de fungos nas sementes sadias situadas a $2 \mathrm{~cm}$ do equipamento; porém, foi incapaz de impedir o desenvolvimento dos fungos tanto nas sementes já deterioradas localizadas próximas do equipamento como em todas as sementes situadas a $30 \mathrm{~cm}$ do aparelho.

Borém et al. (2001a) avaliaram os efeitos do equipamento modificador de atmosfera em contêineres não herméticos, constatando preservação da qualidade das sementes de feijão relacionada à porcentagem de sementes infestadas por insetos (Acanthoscelides obtectus). Estudando o mesmo sistema, Borém et al. (2000) não constataram diferenças significativas entre as médias do número de unidades formadoras de colônia de fungos, amostradas no ar, quando confrontados os dois sistemas.

Os trabalhos desenvolvidos até o presente momento relatam uma capacidade limitada de controle de fungos pelo equipamento redutor de inóculo, além de elucidarem os aspectos relativos ao princípio de funcionamento do equipamento; desta forma, e se considerando sua potencial aplicação em substituição ao uso de produtos tóxicos, sente-se que novos estudos são necessários para otimizar seu funcionamento e obter controle satisfatório de fungos.

O trabalho foi realizado com o objetivo de se avaliar a eficácia do equipamento redutor de inóculo com a redução a esporos de fungos na atmosfera de armazenamento em condições herméticas com temperatura $\left(24^{\circ} \mathrm{C}\right)$ e umidade relativa (87\%) controladas, durante de oito semanas, bem como as condições sanitárias de sementes de feijão, cultivar Pérola, mantidas nestes ambiente e período.

\section{MATERIAL E MÉTODOS}

O trabalho foi desenvolvido nos Laboratórios de Processamento de Produtos Agrícolas do Departamento de Engenharia e de Patologia de Sementes do Departamento de Fitopatologia da Universidade Federal de Lavras.

Utilizaram-se sementes de feijão, cultivar Pérola, produzidas no município de Lavras, MG, colhidas manualmente e trilhadas mecanicamente, quando apresentavam teor de água em torno de $21 \%$ b.u.

As sementes foram acondicionadas e mantidas, durante oito semanas em cilindros herméticos (Figuras 1A, 1B e 2), sendo dois deles com ar tratado a partir de quatro equipamentos redutores de inóculo (ERI) e dois cilindros sem tratamento do ar. Cada cilindro continha $60 \mathrm{~kg}$ de sementes. Amostras para análise de sementes foram obtidas por ocasião do armazenamento e semanalmente, num total de nove 
amostragens. As amostra foram obtidas em três pontos localizados nas alturas 0,10 ; 0,25 e $0,35 \mathrm{~m}$ ao longo do cilindro com o auxílio de um calador. As sementes dessas amostras foram homogeneizadas constituindo-se uma amostra composta.

\section{Estrutura de armazenamento}

A estrutura para armazenamento das sementes de feijão foi composta por quatro conjuntos contendo, em cada um, cilindros, caixa com os ERI, ventilador centrífugo acionado por um motor elétrico, caixa para armazenamento de sais e área de expansão para aumento da pressão estática do ar (Figura 1).

No cilindro com diâmetro de $0,50 \mathrm{~m}$, altura de $1,20 \mathrm{~m}$ e fundo falso em chapa de aço perfurada, foram colocados $60 \mathrm{~kg}$ de sementes, formando uma única camada de 0,40 m

A.

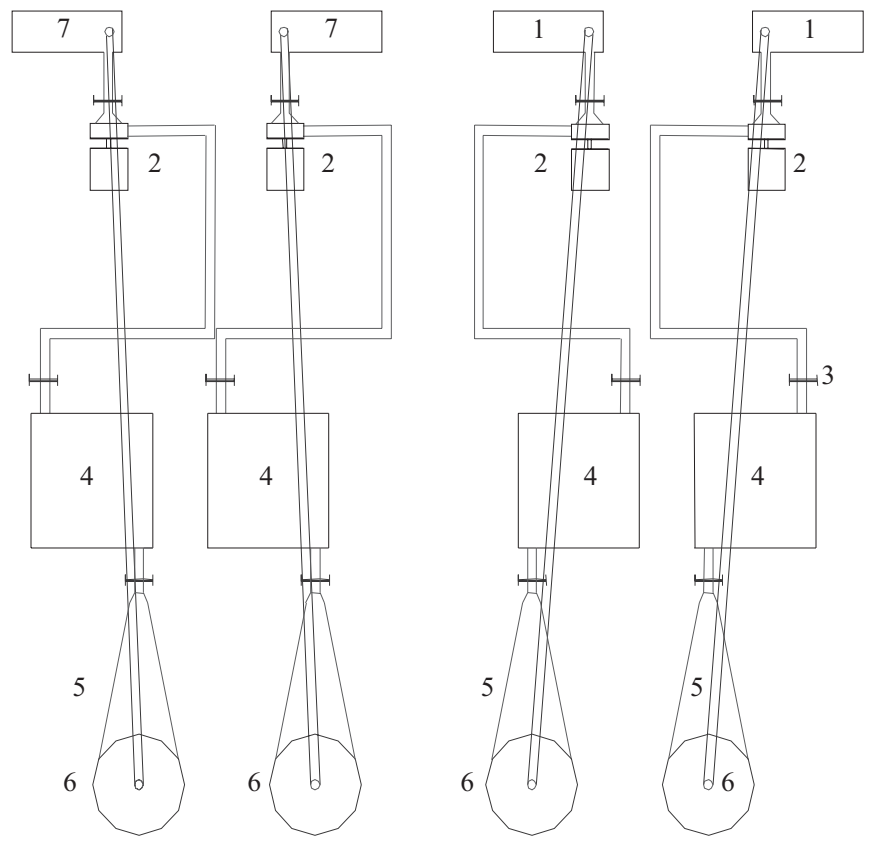

B.

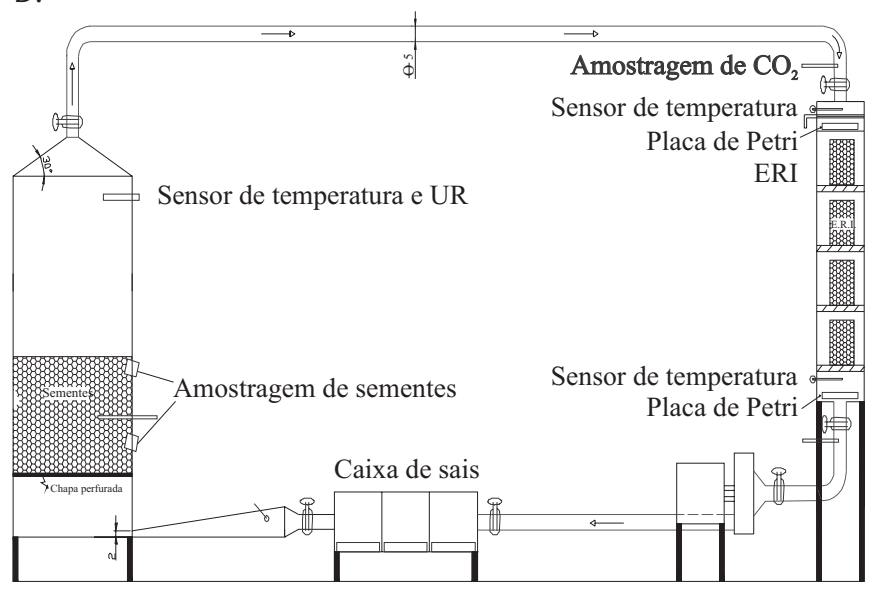

Figura 1. A: (1) caixa com os ERI, (2) ventilador centrífugo e motor, (3) registro de gaveta, união e nipies, (4) caixa de sais, (5) área de expansão, (6) cilindro de sementes, (7) caixa sem os ERI; B: Detalhe do sistema de armazenamento - Vista lateral de espessura. A caixa em que foram instalados os ERI, possuía dimensões de 1,0 x 0,6 x 0,2 m, contendo cinco divisões (Figura 2) as quais serviam de apoio para os ERI e possuíam comprimento de 0,55 m, deixando um espaço livre de 0,05 $\mathrm{m}$ para a passagem do ar. As aberturas foram postas de maneira desencontrada, permitindo a passagem do ar entre a chapa e o direcionando por toda a extensão da caixa.

Promoveram-se duas aberturas laterais de 0,20 x 0,05 m nas partes superior e inferior da caixa para colocação das placas de Petri com meio de cultura (BDA salino), com a finalidade de mostrar a contaminação do ar por fungos. Após a abertura lateral instalou-se um registro em chapa metálica, para minimizar a contaminação do ar, reduzindo o volume da caixa, que entrava em contato com o ambiente externo na ocasião da colocação ou retirada da placa de Petri. Com o auxílio de um suporte, os ERI ficaram suspensos $2 \mathrm{~cm}$ dentro da caixa, para permitir a movimentação do ar no seu interior.

O ventilador centrífugo foi acionado por motor trifásico de alta rotação (3.480 rpm) com potência de 1/3" cv. O fluxo de ar utilizado foi de $1 \mathrm{~m}^{3} \mathrm{~min}^{-1} \mathrm{t}^{-1}$, correspondente ao valor máximo recomendado para aeração de grãos em regiões quentes (Silva et al., 2000). Para medir o fluxo de ar utilizou-se um anemômetro e, para o seu controle, um registro de gaveta. Para manter a umidade relativa no interior do sistema de armazenamento, em torno de $85 \%$, dimensionou-se uma caixa de sais com 0,66 x 0,66 x 0,20 m, na qual foram mantidas bandejas plásticas contendo $2 \mathrm{~kg}$ de cloreto de potássio, $\mathrm{KCl}$ e $250 \mathrm{~mL}$ água destilada, por bandeja.
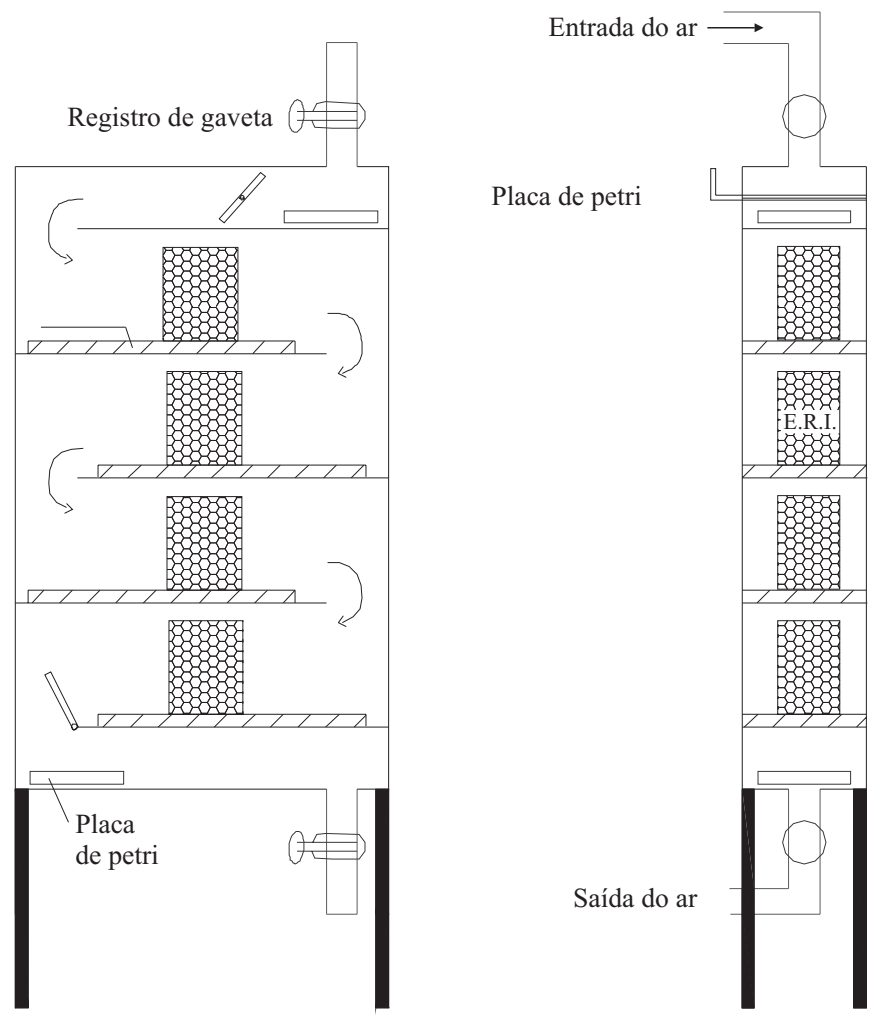

Figura 2. Detalhamento da caixa com os equipamentos redutores de inóculo 
A área de expansão alterou a seção de 0,10 x 0,10 m na saída da caixa de sais, para 0,50 x 0,02 m na entrada do cilindro, ao longo de $0,64 \mathrm{~m}$ de comprimento. Todas as partes foram confeccionadas em chapa de aço carbono $\mathrm{n}^{\circ} 16$ (chapa preta) e pintadas interna e externamente, com fundo especial anticorrosivo e tinta metálica. A união das partes foi realizada com canos de PVC, curvas de $90^{\circ}$ raio longo, registros de gaveta, uniões e nipies, todos com $\varnothing=2$ ”, deixando o sistema hermético, perfazendo um volume interno de $0,5 \mathrm{~m}^{3}$.

\section{Monitoramento da temperatura, umidade relativa e $\mathbf{C O}_{2}$}

A temperatura e a umidade relativa do ar no interior do sistema foram monitoradas diariamente, por meio de sondas instaladas antes do ar atravessar a massa de grãos, na expansão e após sua passagem pelos grãos na parte superior do cilindro acima da massa de grãos. Esses sensores interligados a um termohigrômetro digital, forneceram temperatura e umidade relativa do ar instantaneamente.

O controle da temperatura ambiente foi realizado por meio de um condicionador de ar e a umidade relativa do ar no interior das estruturas foi controlada pela solução salina de cloreto de potássio $(\mathrm{KCl})$. Com o objetivo de se verificar o aumento de temperatura do ar gerado pelos ERI, instalaramse dois termopares em cada uma das caixas, monitorando o ar antes e após sua passagem pelos ERI.

As variações nos níveis de $\mathrm{CO}_{2}$ foram monitoradas diariamente, com o auxílio de um analisador digital de $\mathrm{CO}_{2}$. As leituras das concentrações de $\mathrm{CO}_{2}$ foram realizadas no interior da massa de grãos e na caixa com os ERI, antes e após a passagem do ar pelos equipamentos.

\section{Teor de água das sementes}

$\mathrm{O}$ teor de água das sementes foi determinado utilizandose o método padrão de estufa $105 \pm 1{ }^{\circ} \mathrm{C}$, durante $24 \mathrm{~h}$, segundo as Regras para Análises de Sementes (Brasil, 1992).

\section{Teste de sanidade}

A sanidade das sementes foi avaliada pelo método do papel de filtro (Blotter Test). Empregaram-se 8 repetições de 25 sementes para cada amostra. As sementes foram colocadas adequadamente espaçadas em caixas gerbox contendo papel mata-borrão umedecido com água destilada e meio agarizado salino. Os testes foram realizados sob um regime intermitente de $12 \mathrm{~h}$ de luz e $12 \mathrm{~h}$ de escuro a $25^{\circ} \mathrm{C}$, durante 7 dias.

A avaliação da ocorrência de fungos nas sementes foi realizada sob lupa binocular e microscópio. Para identificação mais segura foram preparadas lâminas com estrutura fúngica para observação sob o microscópio composto. Para a avaliação foram atribuídas notas de zero a três, de acordo com a densidade de inóculos na semente (Borém et al., 2001b). Calculou-se o índice de ocorrência (IO) a partir da fórmula de “Mc Kinney” (apud Borém et al., 2001b) (Eq. 1).

$$
\text { IO }=\Sigma(\text { PO } \times \text { N }) \times 100 /\left(\text { POT } \times N_{\text {máx }}\right)
$$

em que:

IO - índice de ocorrência, \%

PO - porcentagem de ocorrência

$$
\begin{aligned}
& \mathrm{N} \text { - nota } \\
& \text { POT - porcentagem de ocorrência total } \\
& \mathrm{N}_{\text {máx }} \text { - nota máxima }
\end{aligned}
$$

\section{Análise do ar}

A presença de inóculo no ar do interior do cilindro foi monitorada a partir da exposição por $15 \mathrm{~h}$ de placas de Petri com meio BDA salino, autoclavado a $121^{\circ} \mathrm{C}$ durante $20 \mathrm{~min}$, composto de $200 \mathrm{~g}$ de extrato de batata, $40 \mathrm{~g}$ de dextrose, $15 \mathrm{~g}$ de ágar, 60 g de cloreto de sódio e água destilada.

A colocação das placas de Petri no interior da caixa com os ERI utilizaram-se as aberturas laterais e os registros descritos na construção do sistema; durante este procedimento, os ventiladores foram desligados, paralisando a movimentação de ar no sistema e os registros instalados antes e após as aberturas laterais, foram fechados para reduzir o espaço da caixa que entrava em contato com a atmosfera externa. Utilizou-se uma chama próximo às aberturas das placas de Petri, para evitar possíveis contaminações externas. Após essas operações as placas de Petri foram levadas ao laboratório para unificação do desenvolvimento e contagem de culturas fúngicas sobre o BDA salino.

O resultado foi expresso em número de unidades formadoras de colônia de fungos (UFC).

\section{Testes complementares}

Na última semana de armazenamento, efetuaram-se algumas alterações no sistema, objetivando-se uma complementação das análises já realizadas. As amostragens das UFC de fungos foram realizadas diariamente; de início, os ERI foram desligados durante três dias (dias 1, 2 e 3), e religados no quarto dia (dia 4); nos dias seguintes, ainda com os ERI ligados, foram introduzidas modificações no fluxo de ar usado no sistema, sendo alterado para $4,4 \mathrm{~m}^{3} \min ^{-1} \mathrm{t}^{-1}$ (dia 5) e 6,6 $\mathrm{m}^{3} \mathrm{~min}^{-1} \mathrm{t}^{-1}$ (dia 6).

\section{Análises estatísticas}

O delineamento estatístico utilizado foi o inteiramente casualisado em esquema fatorial 2 x 9 com duas repetições (2 tratamentos e 9 épocas de amostragem); realizaram-se análise de variância e teste de médias pelo teste de Tukey, a 5\% de probabilidade, com o auxílio do programa aplicativo SISVAR, segundo Ferreira (2000).

\section{RESULTADOS E DISCUSSÕES}

Monitoramento da umidade relativa, temperatura e $\mathrm{CO}_{2}$

A umidade relativa no interior dos cilindros manteve-se uniforme e com pequenas oscilações ao longo do período de armazenamento, sem sofrer influência das variações da umidade relativa do ar ambiente, devido à presença de uma solução salina saturada de $\mathrm{KCl}$ colocada no interior das estruturas (Figura 3). O valor médio da umidade foi de $87 \%$, condição esta que favorece o desenvolvimento de fungos de armazenamento.

Observa-se, na Figura 4, que o valor médio da temperatura ambiente foi de $24 \pm 2{ }^{\circ} \mathrm{C}$ e a temperatura no interior 


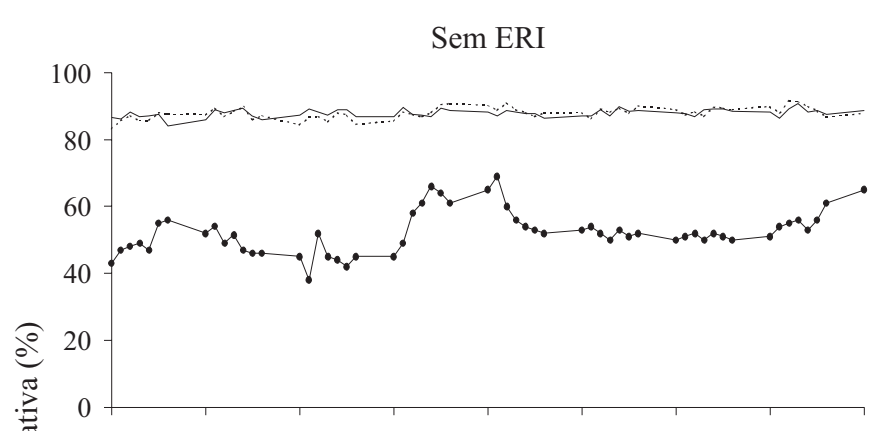

Com ERI

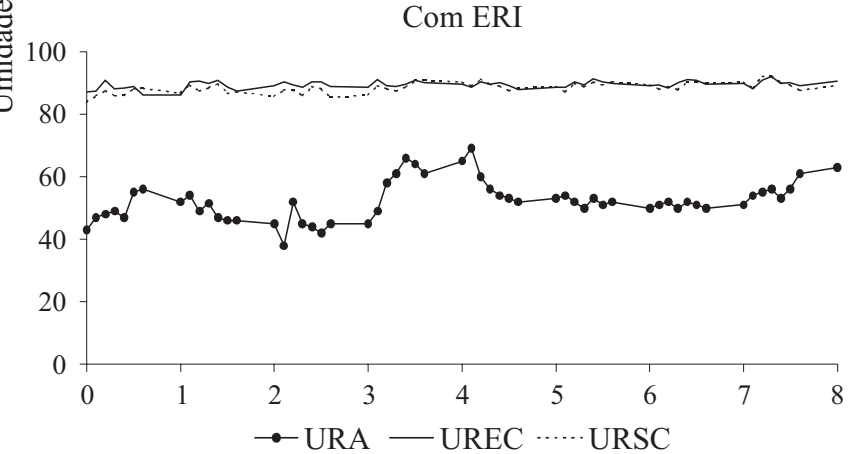

Período de armazenamento (semanas)

Figura 3. Umidades relativas do ar: ambiente (URA); entrada do cilindro (UREC) e saída do cilindro (URSC), na presença e ausência dos equipamentos redutores de inóculo (ERI)

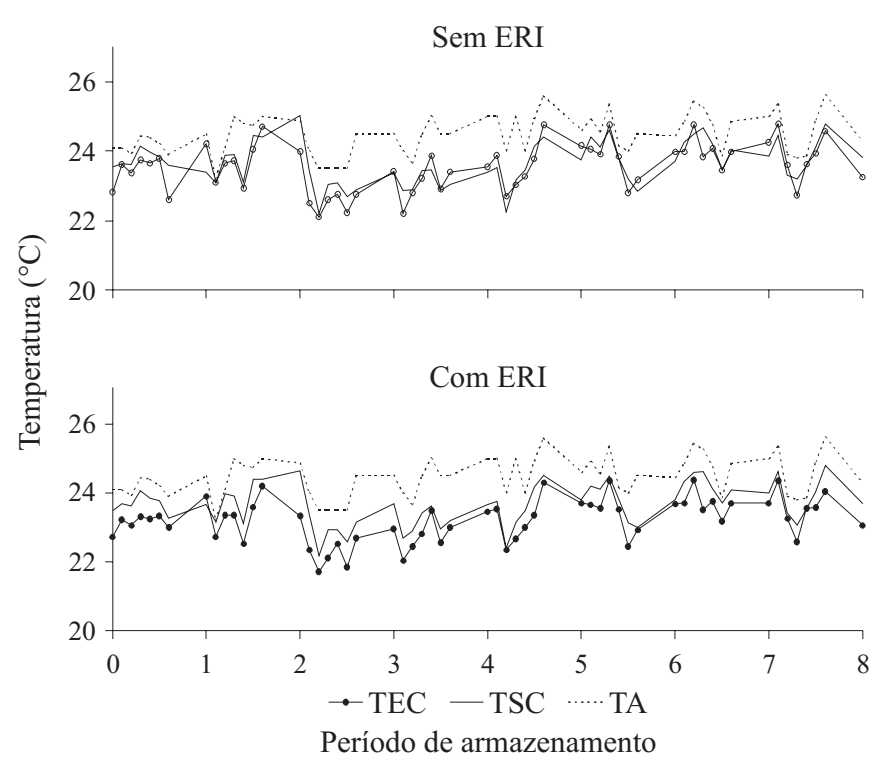

Figura 4. Temperaturas do ar: entrada do cilindro (TEC); saída do cilindro (TSC) e ambiente (TA), na presença e ausência dos equipamentos redutores de inóculo (ERI)

dos cilindros, mesmo na presença do ERI, acompanhou as variações da temperatura ambiente com valores médios de $23 \pm 2{ }^{\circ} \mathrm{C}$, fato que ocorreu em virtude do material de construção dos cilindros (chapa metálica), que permite boa condução térmica.

Os níveis de $\mathrm{CO}_{2}$ da atmosfera no interior da estrutura de armazenamento, aumentaram progressivamente ao longo das épocas (Figura 5).

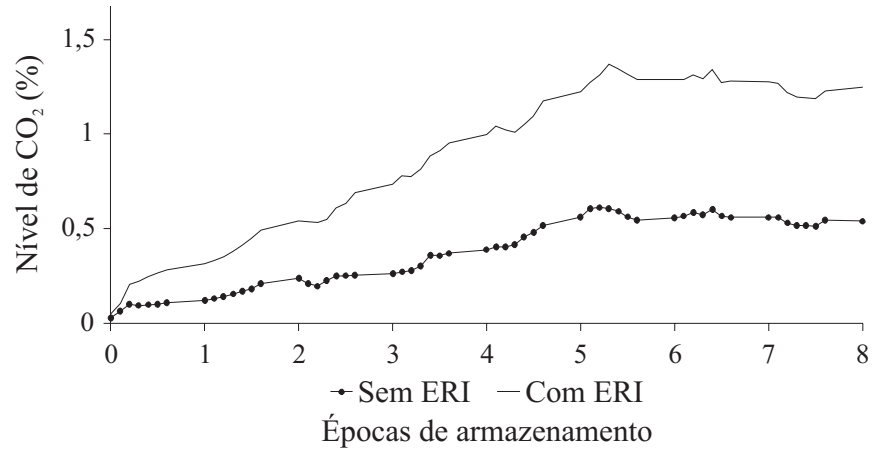

Figura 5. Níveis de $\mathrm{CO}_{2}$ no ar ao longo do período de armazenamento na presença e ausência dos equipamentos redutores de inóculo (ERI)

Nota-se que os níveis de $\mathrm{CO}_{2}$ se apresentaram sempre superiores no sistema, com a presença dos equipamentos redutores de inóculo. Segundo Borém et al. (1998) além da reação de oxidação de compostos orgânicos, o $\mathrm{CO}_{2}$ encontrado na atmosfera no interior da estrutura de armazenamento pode estar sendo produzido também pela degradação do carbonato de cálcio, constituinte do bloco cerâmico, na exposição a temperatura de $325^{\circ} \mathrm{C}$ atingida no interior dos capilares. A partir da sexta semana de armazenamento (Época 5) os níveis de $\mathrm{CO}_{2}$ começaram a decrescer, fato que pode ser explicado em função da diminuição da atividade das sementes.

Ao longo do período de armazenamento, em sua maior parte a presença do ERI resultou em um acréscimo no nível de $\mathrm{CO}_{2}$ em aproximadamente um ponto percentual. Borém et al. (1998) verificaram que a concentração de $\mathrm{CO}_{2}$ no interior de um dessecador contendo um equipamento redutor de inóculo ligado, aumentou em seis vezes o seu valor durante seis horas de funcionamento e que, após o seu desligamento, a concentração de $\mathrm{CO}_{2}$ reduziu drasticamente, retornando ao teor ambiente.

\section{Teor de água das sementes}

O teor de água das sementes (Figura 6) permaneceu em equilíbrio com as condições do ar no interior das estruturas de armazenamento. Desde a quarta semana de armazenamento (Época 4), o teor de água das sementes no cilindro com a presença dos ERI apresentou diferença significativa em relação ao teor de água das sementes sem a presença dos ERI, em decorrência da infecção maior observada a partir deste período.

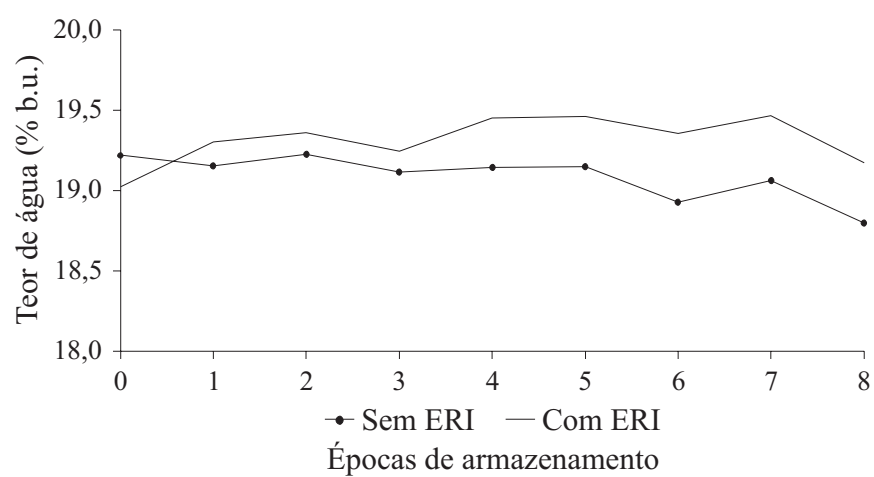

Figura 6. Teor de água das sementes ao longo do período de armazenamento, na presença e ausência dos equipamentos redutores de inoculo (ERI) 


\section{Teste de sanidade}

O índice de ocorrência (IO) de Aspergillus spp e Penicillium spp nas sementes armazenadas na presença dos ERI, está apresentado na Figura 7.

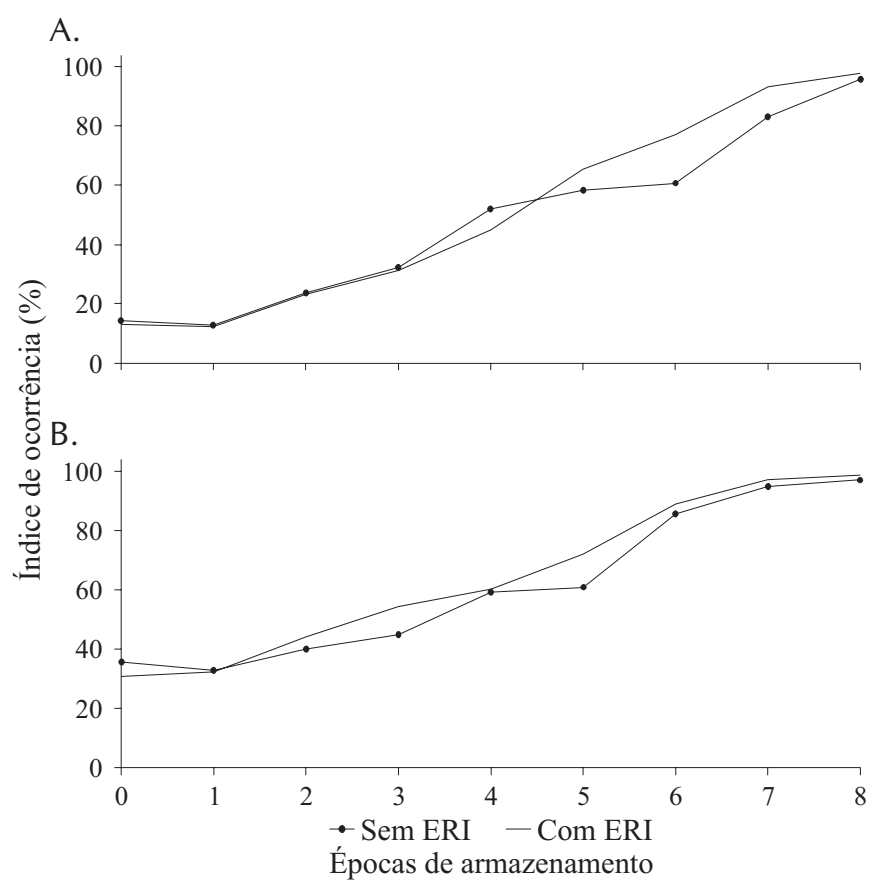

Figura 7. Índice de ocorrência de Aspergillus spp.(A) e Penicillium spp (B) nas sementes ao longo das épocas de armazenamento, na presença e ausência dos equipamentos redutores de inóculo (ERI)

No início do armazenamento, as sementes recém colhidas já apresentavam contaminação pelos fungos Aspergillus spp. e Penicillium spp. Nota-se que o aumento do IO de Aspergillus spp. e Penicillium spp. ao longo das épocas de armazenamento, foi resultado de uma intensa deterioração das sementes, que atingiu um nível máximo ao final do experimento. Por outro lado, observa-se grande semelhança entre as curvas de IO de Aspergillus spp. e Penicillium spp nas duas condições: presença e ausência do ERI, como relatado por diversos outros autores (Borém et al., 2001a; Borém et al., 2001b, Borém et al., 2000).

Na Tabela 1 tem-se os valores médios das porcentagens do índice de ocorrência de Aspergillus spp. e Pencillium spp nas sementes armazenadas com e sem a presença dos ERI, ao longo das nove épocas de armazenamento.
A partir da Época 5, os valores médios do IO de Aspergillus spp. nas sementes com a presença dos ERI foi significativamente $(\mathrm{P}<0,05)$ maior que na sua ausência, exceto na época 8, devido à intensa deterioração ocasionada pelos microrganismos verificada em grande intensidade a partir desta época. Deste modo, os ERI não foram eficientes no controle de Aspergillus spp já existentes nas sementes.

O índice de ocorrência de Penicillium spp nas sementes foi significativamente $(\mathrm{P}<0,05)$ maior na presença dos ERI, nas Épocas 2, 3, 5 e 7. Os equipamentos redutores de inóculo foram incapazes de impedir, ou mesmo diminuir, a infecção de Penicillium spp nas sementes armazenadas em condições favoráveis ao desenvolvimento desses microrganismos, contrapondo-se aos resultados encontrados por Baez (1993) que verificou diminuição do número de colônias de fungos nos grãos de milho na presença do equipamento modificador de atmosfera, armazenados em condições controladas de temperatura $\left(30^{\circ} \mathrm{C}\right)$ e umidade relativa (93\%). Neste trabalho, porém, as bandejas contendo o produto foram colocadas próximas ao equipamento modificador de atmosfera, em uma única câmara. Durante o teste de sanidade das sementes foram observados também outros organismos, além dos fungos de armazenamento. Ocorreu o aparecimento ocasional sem quantificação de Phoma spp, Fusarium spp, Rhizopus spp Cladosporium spp e Alternaria spp.

\section{Análise do ar}

Observa-se, na Figura 8, que a temperatura do ar no interior da caixa com a presença dos ERI seguiu a tendência da temperatura ambiente, mas com valores sempre superiores.

Na entrada da caixa, a temperatura média do ar permaneceu em torno de $36^{\circ} \mathrm{C}$ e, na saída da caixa, em torno de $32^{\circ} \mathrm{C}$, fato este que se deve à energia radiante liberada pelo funcionamento do equipamento. Sem a presença do ERI os valores médios de temperatura do ar na entrada e saída da caixa acompanharam as variações da temperatura ambiente controlada por meio do condicionador de ar, em razão da boa condução térmica das chapas metálicas usadas na construção do sistema.

A tubulação utilizada para conduzir o ar apresentava uma seção de $20,25 \mathrm{~cm}^{2}$; ao ser conectada à caixa com os ERI, esta seção foi transformada para $400 \mathrm{~cm}^{2}$. Desta forma, a velocidade do ar no interior da caixa foi reduzida

Tabela 1. Índice de ocorrência (\%) de Aspergillus spp. e Penicillium spp nas sementes armazenadas na presença e ausência dos ERI ao longo das nove épocas

\begin{tabular}{|c|c|c|c|c|c|c|c|c|c|}
\hline \multirow{2}{*}{ Tratamentos } & \multicolumn{9}{|c|}{ Épocas de Armazenamento } \\
\hline & 0 & 1 & 2 & 3 & 4 & 5 & 6 & 7 & 8 \\
\hline & \multicolumn{9}{|c|}{ Aspergillus spp } \\
\hline Sem ERI & $14,24 a$ & $12,74 a$ & $23,58^{a}$ & $32,16 a$ & $51,91 b$ & $58,33 a$ & $60,66 a$ & $83,16 a$ & $95,66 \mathrm{a}$ \\
\hline \multirow[t]{2}{*}{ Com ERI } & $13,16 a$ & $12,16 a$ & $23,24^{\mathrm{a}}$ & $31,16 a$ & $44,99 a$ & $65,24 b$ & $76,91 b$ & $93,16 b$ & $97,66 \mathrm{a}$ \\
\hline & \multicolumn{9}{|c|}{ Penicillium spp } \\
\hline Sem ERI & $35,58 b$ & $32,74 a$ & $39,91^{a}$ & $44,83 a$ & $59,00 \mathrm{a}$ & $60,74 a$ & $85,58 a$ & $94,83 a$ & $96,91 \mathrm{a}$ \\
\hline Com ERI & $30,58 a$ & $32,24 a$ & $43,91 b$ & $54,16 b$ & $60,16 a$ & $72,08 b$ & $88,91 b$ & $97,08 \mathrm{a}$ & $98,58 \mathrm{a}$ \\
\hline
\end{tabular}

Médias seguidas pela mesma letra na coluna não diferem entre si a $5 \%$ de probabilidade, pelo teste Tukey 


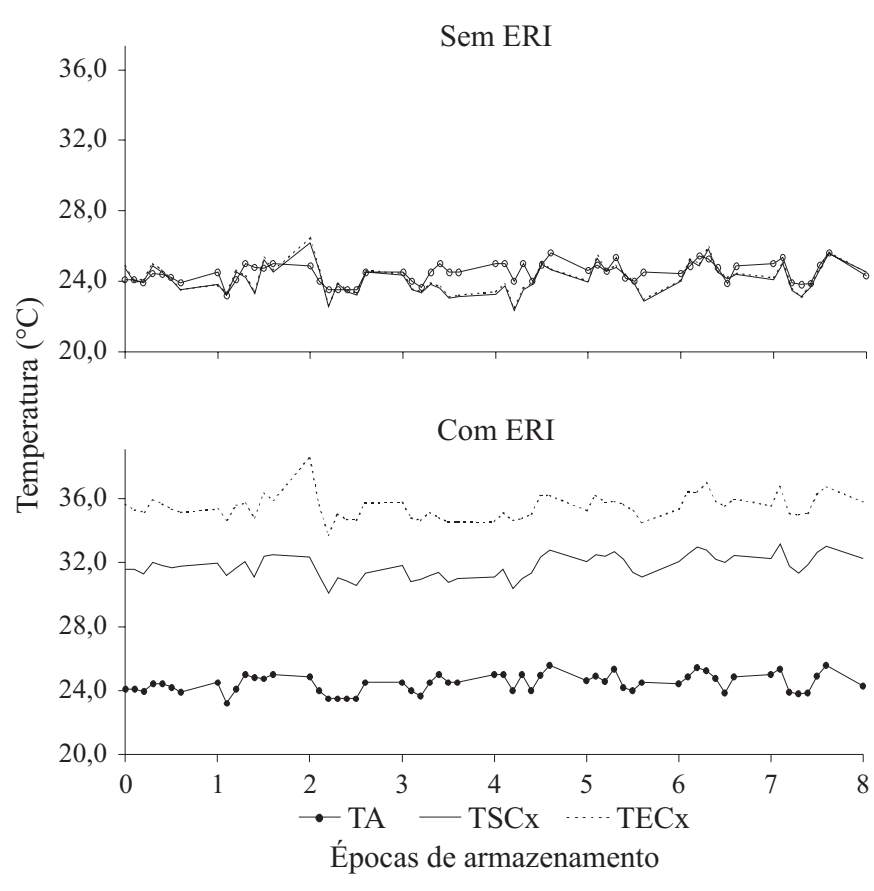

Figura 8. Temperatura do ar: ambiente (TA); saída da caixa (TSCx) e entrada da caixa (TECX), ao longo das 9 épocas de amostragem, na presença e ausência dos equipamentos redutores de inoculo (ERI)

drasticamente, facilitando a formação de correntes de convecção natural pelo aquecimento do ERI possibilitando, assim, a passagem do ar através dos seus filamentos, sem haver o seu resfriamento. O fluxo de ar de $1 \mathrm{~m}^{3} \mathrm{~min}^{-1} \mathrm{t}^{-1}$ provavelmente tenha sido incapaz de deslocar essas massas de ar aquecido através dos compartimentos da caixa contra a força da gravidade, justificando os maiores valores de temperatura encontrados na parte superior da caixa (entrada); os resultados não possuem relatos anteriores, colaborando na compreensão do funcionamento do ERI e sua possível aplicação em escala real.

\section{Contagem de unidades formadoras de colônia (UFC) no ar}

Pelos resultados apresentados na Tabela 2, observa-se um aumento substancial no número de UFC de Aspergillus spp e Penicillium spp presentes na atmosfera no interior do sistema, ao longo das épocas de armazenamen- to; entretanto, nas amostragens realizadas na entrada da caixa com a presença dos equipamentos redutores de inóculo, não foram encontradas unidades formadoras de colônias, com exceção da primeira semana (épocas zero e 1), ressaltando-se que na época zero a amostragem foi realizada antes da colocação das sementes nos cilindros e, na época 1, com as sementes acomodadas, possivelmente não houve tempo suficiente para ocorrer uma atuação eficaz dos equipamentos.

Nas épocas seguintes verificou-se o efeito dos equipamentos sobre os esporos de fungos presentes no ar, evitando seu aparecimento, mesmo em temperaturas na faixa ótima para o desenvolvimento de fungos de armazenamento, 28 e $35^{\circ} \mathrm{C}$. Segundo Hara (1991), citado por Borém et al (2001b), este efeito está relacionado à oxidação do material orgânico presente no ar, que passa através dos capilares do equipamento redutor de inóculo.

\section{Testes complementares}

Monitoramento da temperatura. A temperatura do ar, tanto na entrada como na saída da caixa com os equipamentos redutores de inóculo (Figura 9), acompanhou a temperatura ambiente nos dias 1, 2 e 3 (equipamentos desligados). Novamente com os equipamentos ligados (dia 4), ocorreu aumento da temperatura do ar no interior da caixa, embora a temperatura da entrada fosse superior à da saída.

Nos dias 5 e 6, com os equipamentos ligados e se aumentando o fluxo de ar no interior do sistema de $1 \mathrm{~m}^{3} \mathrm{~min}^{-1} \mathrm{t}^{-1}$ para 4,4 e 6,6 $\mathrm{m}^{3} \mathrm{~min}^{-1} \mathrm{t}^{-1}$, ocorreu inversão nos valores das temperaturas, observando-se valores superiores na saída da caixa; deste modo, pode-se observar, com o aumento do fluxo de ar, deslocamento da energia radiante emitida pelos ERI da entrada para a saída da caixa.

Na caixa sem os ERI, a temperatura do ar no interior do sistema acompanhou as variações da temperatura ambiente, como já verificado durante o período de armazenamento.

Unidades formadoras de colônias no ar. Na Tabela 3 verificou-se, com os equipamentos desligados (1, 2 e 3) aumento das unidades formadoras de colônia de Aspergillus spp e Penicillium spp mesmo onde anteriormente não foram encontradas (entrada da caixa com ERI).

Tabela 2. Unidades formadoras de colônias no ar contendo Aspergillus spp e Penicillium spp amostrados antes e após a passagem do ar pelo equipamento redutor de inóculo, ao longo do período de armazenamento, durante as 9 épocas de amostragem

\begin{tabular}{|c|c|c|c|c|c|c|c|c|c|c|}
\hline \multirow{2}{*}{\multicolumn{2}{|c|}{ Tratamentos }} & \multicolumn{9}{|c|}{ Épocas de Armazenamento } \\
\hline & & 0 & 1 & 2 & 3 & 4 & 5 & 6 & 7 & 8 \\
\hline & & \multicolumn{9}{|c|}{ Aspergillus spp } \\
\hline \multirow{2}{*}{ Sem ERI } & Entrada & 0 & 10 & 11 & 29 & 59 & 68 & 121 & 212 & 506 \\
\hline & Saída & 1 & 8 & 6 & 29 & 42 & 88 & 163 & 215 & 491 \\
\hline \multirow{2}{*}{ Com ERI } & Entrada & 0 & 10 & 0 & 0 & 0 & 0 & 0 & 0 & 0 \\
\hline & Saída & 1 & 11 & 2 & 35 & 29 & 83 & 123 & 122 & 328 \\
\hline & & \multicolumn{9}{|c|}{ Penicillium spp } \\
\hline \multirow{2}{*}{ Sem ERI } & Entrada & 0 & 27 & 15 & 85 & 131 & 171 & 254 & 244 & 380 \\
\hline & Saída & 0 & 27 & 22 & 108 & 160 & 219 & 255 & 198 & 374 \\
\hline \multirow{2}{*}{ Com ERI } & Entrada & 0 & 29 & 0 & 0 & 0 & 0 & 0 & 0 & 0 \\
\hline & Saída & 0 & 17 & 2 & 47 & 58 & 147 & 168 & 97 & 236 \\
\hline
\end{tabular}




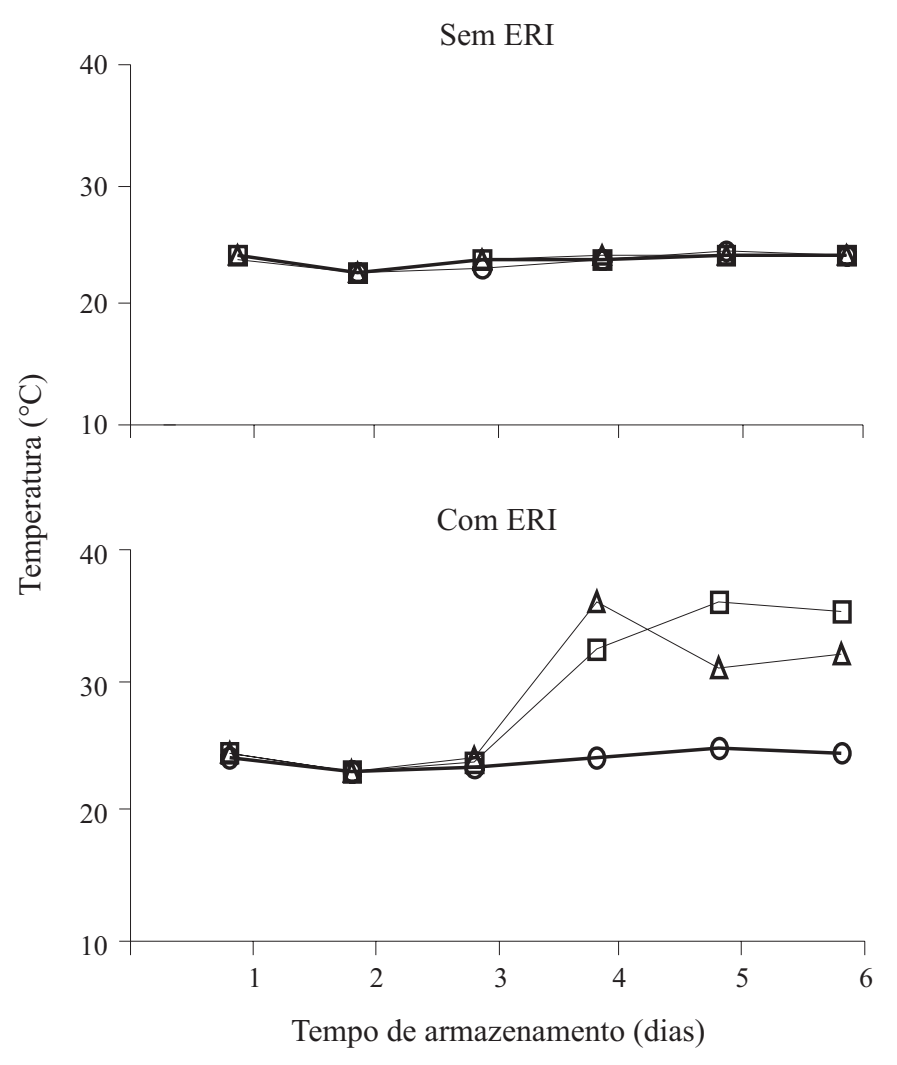

Figura 9. Temperatura do ar: ambiente (TA); saída da caixa (TSCx); entrada da caixa (TECX), nas condições diárias após a época 8: 1, 2, e 3 dos equipamentos redutores de inoculo (ERI desligado); 4 (ERI ligado); 5 (ERI ligado e com fluxo de ar de $4,4 \mathrm{~m}^{3} \mathrm{~min}^{-1} \mathrm{t}^{-1}$ ); 6 (ERI ligado e com fluxo de ar de $6,6 \mathrm{~m}^{3} \mathrm{~min}^{-1} \mathrm{t}^{-1}$ )

Após serem ligados novamente (quarto dia), nota-se que na entrada da caixa com os ERI novamente não aparecem UFC, confirmando o efeito do ERI neste local, enquanto nas amostragens realizadas nos dias 5 e 6 , ainda com os ERI ligados e com o fluxo de ar maior, nota-se que o não aparecimento de UFC observado na entrada foi transferido para a saída da caixa.

Analisando-se os valores de temperatura e os dados de UFC de fungos no ar após o aumento do fluxo de ar do sistema, algumas considerações a respeito do efeito esterili- zador do ERI podem ser consideradas; imagina-se que seria como uma bolha de ar protetora que pode restringir o aparecimento de inóculo de fungos no seu raio de ação. Esta bolha pode ser deslocada e direcionada em ambientes fechados, de acordo com as condições de movimentação de ar, porém esta restrição ao desenvolvimento de fungos possui alcance limitado, atingindo pequenas extensões e exigindo grande número de unidades do ERI, para aumentar sua área de ação.

\section{CONCLUSÕES}

1. O equipamento redutor de inóculo é eficaz quanto ao controle dos fungos presentes no ar.

2. O efeito do equipamento redutor de inóculo no controle de fungos presentes no ar é deslocado com a alteração do fluxo de ar utilizado no sistema.

3. O equipamento redutor de inóculo é incapaz de controlar os fungos de armazenamento, Aspergillus spp e Penicillium spp, presente nas sementes.

\section{AgRADECIMENTOS}

Os autores agradecem à Fundação de Amparo à Pesquisa do Estado de Minas Gerais (FAPEMIG) pelo apoio financeiro indispensável para realização do trabalho e ao Conselho Nacional de Pesquisa e Desenvolvimento (CNPq) pela bolsa concedida ao primeiro e segundo autores.

\section{LITERATURA CITADA}

Baez, J. E. A. Efeito de um equipamento modificador de atmosfera na conservação de grãos de milho. Viçosa: UFV, 1993, 51p. Dissertação Mestrado

Borém, F. M.; Hara, T.; Silva, R. F. Alterações químicas e físicas provocadas no ar de armazenamento por um equipamento modificador de atmosfera. Revista Brasileira de Armazenamento, Viçosa, v.23, n.1, p.16-27, 1998.

Tabela 3. Contagem de unidades formadoras de colônias Aspergillus spp. e Penicillium spp antes e após a passagem do ar pelos ERI, nas condições diárias após a época 8: 1, 2 e 3 (ERI desligados); 4 (ERI ligados); 5 (ERI ligados e com fluxo de ar de 4,4 $\mathrm{m}^{3} \mathrm{~min}^{-1} \mathrm{t}^{-1}$ ); 6 (ERI ligados e com fluxo de ar de $\left.6,6 \mathrm{~m}^{3} \mathrm{~min}^{-1} \mathrm{t}^{-1}\right)$

\begin{tabular}{|c|c|c|c|c|c|c|c|}
\hline \multirow{2}{*}{\multicolumn{2}{|c|}{ Tratamentos }} & \multicolumn{6}{|c|}{ Tempo de Armazenamento (dias) } \\
\hline & & 1 & 2 & 3 & 4 & 5 & 6 \\
\hline & & \multicolumn{6}{|c|}{ Aspergillus spp } \\
\hline \multirow{2}{*}{ Sem ERI } & Entrada & 899 & 770 & 770 & 595 & 1126 & 1105 \\
\hline & Saída & 808 & 773 & 791 & 553 & 1234 & 1318 \\
\hline \multirow{2}{*}{ Com ERI } & Entrada & 1233 & 978 & 1190 & 0 & 103 & 723 \\
\hline & Saída & 893 & 978 & 723 & 468 & 0 & 0 \\
\hline & & \multicolumn{6}{|c|}{ Penicillium spp } \\
\hline \multirow{2}{*}{ Sem ERI } & Entrada & 226 & 292 & 297 & 149 & 329 & 258 \\
\hline & Saída & 166 & 238 & 274 & 372 & 289 & 210 \\
\hline \multirow{2}{*}{ Com ERI } & Entrada & 106 & 255 & 468 & 0 & 11 & 128 \\
\hline & Saída & 510 & 468 & 298 & 179 & 0 & 0 \\
\hline
\end{tabular}


Borém, F. M.; Silva, R. F.; Hara, T.; Machado, J. C. Ocorrência de fungos no ar e em sementes de feijão (Phaseolus vulgaris L.) armazenadas em ambientes com equipamento modificador da atmosfera. Ciência e Agrotecnologia, Lavras, v.24, n.1, p.195-202, 2000.

Borém, F. M; Hara, T; Silva, R. F; Teixeira,V. H. Qualidade de sementes de feijão (Phaseolus vulgaris L.) armazenadas com um equipamento modificador de atmosfera. Revista Brasileira de Armazenamento, Viçosa, v.26, n.1, p.16-27, 2001a.

Borém, F. M.; Silva, R. F.; Hara, T.; Machado, J. C. Efeito de um equipamento modificador de atmosfera no estabelecimento de fungos em sementes de feijão (Phaseolus vulgaris L.) em ambientes de elevada temperatura e umidade relativa. Revista Brasileira de Produtos Agroindustriais, Campina Grande, v.3, n.1, p.13-20, 2001b.

Brasil. Ministério da Agricultura e Reforma Agrária. Secretaria Nacional de Defesa Agropecuária. Regras para análise de sementes. Brasília, 1992. 365p.

Carvalho, M. L. M.; Von Pinho, E. V. R. Armazenamento de sementes. Curso de Pós-Graduação "Lato Sensu” (Especialização) a Distância: Produção e Tecnologia de Sementes. Lavras: UFLA/FAEPE, 1997. 67p.

Christensen, C. M. Storage of cereal grains and their products. Minnesota: American Association of Cereal Chemists, 2 ed.,1974.
Dhingra, O. D. Prejuízos causados por microrganismos durante o armazenamento de sementes. Revista Brasileira de Sementes, Brasília, v.7, n.1, p.139-145, 1985.

Ferreira, D. F. Análises estatísticas por meio do Sisvar para Windows versão 4.0. In: Reunião Anual da Região Brasileira da Sociedade Internacional de Biometria. UFScar, 45, 2000. São Carlos. Anais... São Carlos: UFSCar, 2000, p.255-258.

Hara,T.; Baggio, D.; Fiorenzano, A.; Seródio, R. S.; Abreu, J. M.; Ribeiro, N. C. A. Armazenamento de cacau comercial em contêiner equipado com esterilizador de ar termo-iônico. Boletim Brasileiro de Pós-colheita. Convenção Nacional da Associação Brasileira de Pós-Colheita. 1990, ABRAPÓS, Anais ... Curitiba:1990. p.4-31, Edição especial.

Machado, J. C. Tratamento de sementes no controle de doenças. Lavras: LAPS/UFLA/FAEPE, 2000. 13p.

Neergaard, P. Seed pathology. London: MacMillan, 1979. 2p.

Novembre, A. D. L. C. Tratamento fungicida e conservação de sementes de feijoeiro (Phaseolus vulgaris L.). Piracicaba: ESALQ, 1987. 147p. Dissertação Mestrado

Silva, J. S.; Lacerda Filho, A. F.; Devilla, I. A. Aeração de grãos armazenados. In: Silva, J. S. (ed.). Secagem e armazenagem de produtos agrícolas. Viçosa: Aprenda Fácil, 2000. cap.11, p.261-277. 